\title{
Validity of Reversible Flow Lanes between Kandy Road Flyover and New Kelani Bridge Roundabout along A01 to Accommodate Peak Traffic Flows
}

\section{K. S. Weerasekera}

\begin{abstract}
This paper examines ways of enhancing road capacity by improving lane efficiency along Colombo-Kandy Road (A01) at Colombo city entrance by introducing reversible traffic flow lanes between Kandy road flyover at Pattiya junction and New Kelani Bridge roundabout, to cater for peak traffic flows. A traffic study was conducted between Pattiya junction and New Kelani Bridge roundabout to find out the benefits and any losses, if reversible traffic flow lanes are introduced along this stretch of road during peak traffic flows in mornings and evenings. Two options of lane assignment were considered for the heavy flow direction during peak hours. Option ( i ) by adding one extra mixed traffic lane towards the heavy flow direction while reducing a lane from the opposite direction, and option ( ii ) adding an additional lane exclusively for buses towards the heavy flow direction while reducing a lane in the opposite direction. These two options were considered for both morning and evening peak traffic flows. By using Davidson's model the benefits or any losses in travel time was computed for the two options separately for both directional peak traffic flows.
\end{abstract}

The study proved that by the introduction of reversible flow lanes along the considered section, during morning and evening peak traffic flows, the benefits obtained by far outweigh the losses due to minor reduction in road capacity in the opposite directional traffic flows. It was also found that introduction of designated lanes for 'buses only' further improves the overall efficiency of the system with higher benefits. If 'buses only' lanes are introduced it is of the utmost importance to implement these lanes only for buses, as expected.

Keywords: $\quad$ Reversible Flow Lanes, Contra Flow, Tidal Flow, Bus Lanes

\section{Introduction}

Colombo - Kandy road (A01), is one of the main arterial roads of Sri Lanka radiating from Colombo, which carries traffic travelling towards the central hills as well as northern and north central areas of the country. Hence, this is one of the busiest roads in Sri Lanka which links Colombo with other major areas of the island. The inbound traffic towards Colombo is very heavy during the morning peak hours near the city entry, and severe congestion of traffic is experienced during the week days (Figure 1). Similar conditions are observed during evening peak hours on weekdays in the outbound direction. This traffic congestion costs the state dearly by means of increased travel time, fuel wastage, vehicle wear and tear, loss of safety, pollution of air and noise etc.

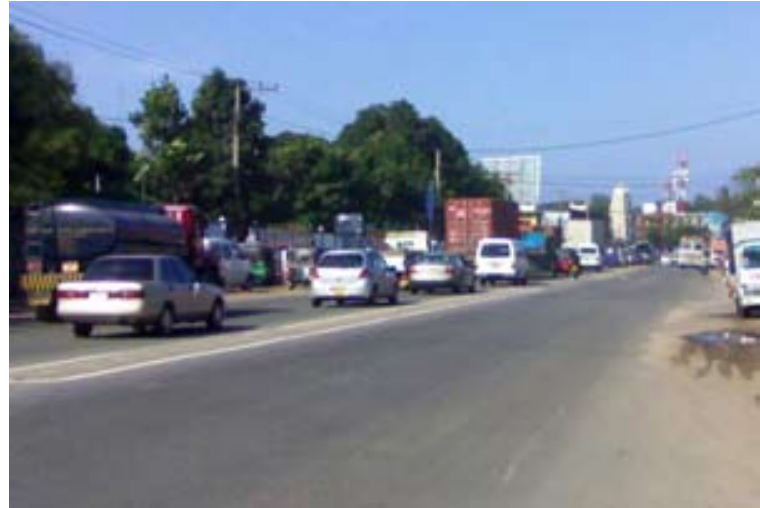

Figure 1 - Inbound Traffic towards Colombo

A newly built flyover above the main railway line at Pattiya junction is of four lanes with two lanes in either direction (Figure 2). The distance from the flyover to the New Kelani Bridge roundabout is $2 \mathrm{~km}$. This stretch of $2 \mathrm{~km}$ road consists of six lanes in an undivided

Eng. (Prof.) K. S. Weerasekera, BSc Eng (Moratuwa) MEngSc (UNSW), PhD (UNSW), FIE (Sri Lanka), CEng, IntPE(SL), MIE (Aust), CPEng, MIHT (UK), MASCE, Professor in Civil Engineering, Department of Civil Engineering, The Open University of Sri Lanka. 
carriageway with 3 lanes in either direction.

With the introduction of the new flyover at Pattiya junction the interruption to A01 traffic arising from frequent rail gate closures of the main railway line has been eliminated, but the congestion between Pattiya junction and the New Kelani Bridge roundabout has not reduced.

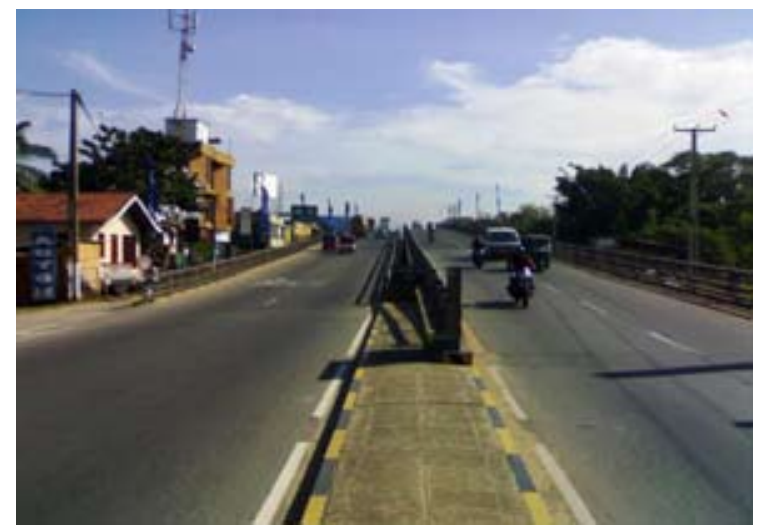

Figure 2 - Pattiya Junction Flyover along A01

It is observed that during peak flows, the traffic towards the heavy direction is extremely heavy, but in the opposite direction the road space is not utilised effectively (see Figure 1). Hence, this study intends to investigate the benefits that could be reaped by introducing reversible or contra flow traffic flow lanes.

\section{Reversible Traffic Flow Lanes or Contra Flow Lanes}

In busy arterial roads, when the movement of traffic is very heavy in one direction during a certain period of the day, and also becomes very heavy in the opposite direction during another time of the day, this phenomenon is commonly termed as 'tidal flow'. As a solution to address the tidal flows reversible lanes can be introduced. A reversible lane is one, where the direction of traffic movement is changed according to the intensity of traffic flow in a particular direction (Kadiyali [1]; Salter \& Hounsell [2]).

\section{Traffic Data Collection}

A manual classified traffic count was performed for 16 hours at a location at $1 \mathrm{~km}$ south of Pattiya junction flyover (i.e. towards Colombo) on a normal working day from 6:00AM to 10:00PM. Two-directional traffic was recorded separately at 15 minute intervals at the counting location for 7 different categories of vehicles.

The seven broad categories of vehicles were; three-wheelers, cars \& SUVs, all vans, all types of buses, goods carrying vehicles, all vehicles with 3 axles, and vehicle with 4 axles or more as indicated in Tables 1 \& 2. The Passenger Car Unit (PCU) factors based on RDA records, for these separate categories of vehicles on flat terrain roads with multiple lanes are indicated in Table 3.

Table 1 - Hourly Traffic Volume (To Colombo) at Peliyagoda on A01

\begin{tabular}{|l|r|r|r|r|r|r|r|r|}
\hline Time & TWL & CAR & VAN & BUS & GV & \multicolumn{1}{c|}{ A } & $\geq 4$ & Total \\
\hline $6-7$ & 284 & 946 & 423 & 414 & 129 & 17 & 6 & 2218 \\
$7-8$ & 644 & 1481 & 399 & 352 & 167 & 2 & 8 & 3052 \\
$8-9$ & 503 & 1076 & 195 & 217 & 220 & 7 & 7 & 2224 \\
$9-10$ & 411 & 863 & 162 & 184 & 245 & 2 & 21 & 1890 \\
$10-11$ & 333 & 694 & 146 & 155 & 219 & 14 & 10 & 1572 \\
$11-12$ & 502 & 468 & 189 & 197 & 195 & 11 & 28 & 1589 \\
$12-13$ & 421 & 541 & 230 & 233 & 169 & 13 & 31 & 1639 \\
$13-14$ & 428 & 407 & 233 & 210 & 176 & 22 & 20 & 1495 \\
$14-15$ & 321 & 562 & 175 & 197 & 160 & 10 & 17 & 1441 \\
$15-16$ & 354 & 571 & 170 & 225 & 163 & 12 & 20 & 1515 \\
$16-17$ & 294 & 504 & 226 & 209 & 188 & 18 & 14 & 1453 \\
$17-18$ & 224 & 485 & 266 & 256 & 97 & 14 & 21 & 1363 \\
$18-19$ & 305 & 484 & 204 & 309 & 118 & 13 & 26 & 1459 \\
$19-20$ & 303 & 478 & 161 & 225 & 101 & 17 & 17 & 1301 \\
$20-21$ & 165 & 311 & 166 & 186 & 91 & 24 & 15 & 958 \\
$21-22$ & 135 & 265 & 149 & 148 & 66 & 15 & 9 & 788 \\
\hline & & & & & & & & \\
$\mathbf{6 - 2 2}$ & $\mathbf{5 6 2 7}$ & $\mathbf{1 0 1 3 6}$ & $\mathbf{3 4 9 3}$ & $\mathbf{3 7 1 7}$ & $\mathbf{2 5 0 4}$ & $\mathbf{2 1 1}$ & $\mathbf{2 6 7}$ & $\mathbf{2 5 9 5 5}$ \\
\hline
\end{tabular}

Table 2 - Hourly Traffic Volume (To Kandy) at Peliyagoda on A01

\begin{tabular}{|l|r|r|r|r|r|r|r|r|}
\hline Time & TWL & CAR & VAN & BUS & GV & 3 AV & $\geq 4 A$ & Total \\
$6-7$ & 118 & 196 & 112 & 189 & 90 & 2 & 3 & 710 \\
$7-8$ & 304 & 328 & 152 & 216 & 100 & 21 & 25 & 1146 \\
$8-9$ & 251 & 309 & 114 & 226 & 171 & 3 & 10 & 1084 \\
$9-10$ & 250 & 287 & 119 & 188 & 234 & 17 & 20 & 1114 \\
$10-11$ & 330 & 400 & 173 & 184 & 295 & 14 & 18 & 1414 \\
$11-12$ & 337 & 402 & 175 & 237 & 307 & 11 & 15 & 1484 \\
$12-13$ & 327 & 352 & 169 & 267 & 272 & 11 & 21 & 1419 \\
$13-14$ & 367 & 423 & 264 & 270 & 286 & 7 & 24 & 1641 \\
$14-15$ & 234 & 439 & 349 & 284 & 245 & 13 & 19 & 1584 \\
$15-16$ & 380 & 450 & 216 & 230 & 310 & 12 & 22 & 1620 \\
$16-17$ & 245 & 517 & 240 & 282 & 343 & 20 & 20 & 1668 \\
$17-18$ & 250 & 928 & 311 & 290 & 254 & 12 & 23 & 2068 \\
$18-19$ & 403 & 1024 & 323 & 300 & 211 & 21 & 14 & 2296 \\
$19-20$ & 433 & 1252 & 377 & 340 & 210 & 22 & 19 & 2653 \\
$20-21$ & 334 & 649 & 242 & 260 & 209 & 19 & 29 & 1741 \\
$21-22$ & 279 & 515 & 210 & 220 & 156 & 12 & 26 & 1419 \\
\hline & & & & & & & & \\
$6-22$ & 4841 & 8471 & 3548 & 3983 & 3694 & 217 & 308 & $\mathbf{2 5 0 6 1}$ \\
\hline
\end{tabular}


Table 3 - Equivalent Passenger Car Units (PCU) for Flat Terrain Multiple Lane Roads

\begin{tabular}{|c|c|c|c|c|c|c|}
\hline TWL & CAR & VAN & BUS & GV & $3 \mathrm{~A}$ & $\geq 4 \mathrm{~A}$ \\
\hline 0.8 & 1.0 & 1.5 & 2.0 & 1.7 & 2.8 & 3.5 \\
\hline
\end{tabular}

A separate short duration vehicle occupancy count was conducted during peak hours to observe the average number of passengers carried by different categories of vehicles.

Peak hour average passenger count indicated that, the average occupancy of a bus is around 40 passengers and all other vehicles considered as a mix is around 3.25 passengers per vehicle. These values were used for computing vehicle occupancy in the study.

Figure 3 shows two-directional hourly traffic flows separately, and also the total hourly traffic flow along the considered road section over the counting period from 6:00AM to 10:00PM.

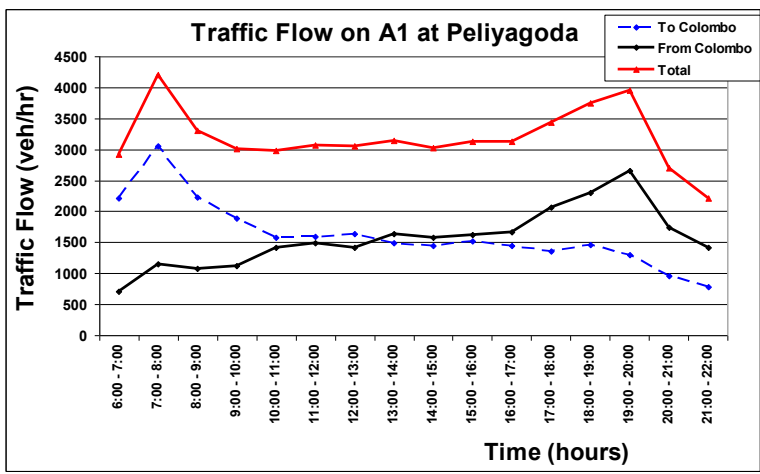

\section{Figure 3 - Hourly Traffic Flows on A01 at Peliyagoda}

\section{Methodology \& Analysis}

From the traffic survey results it was identified that the morning peak is from 7:00AM to 8:00AM and the total vehicle volume towards Colombo is around $3050 \mathrm{vph}$. During the morning peak the total vehicle volume travelling out of Colombo was around $1150 \mathrm{vph}$ (see Figure 3). The total two directional flow was around $4200 \mathrm{vph}$.

Similarly, the out-bound traffic reaches its peak in the evening between 7:00PM to 8:00PM and the volume is around $2650 \mathrm{vph}$. During the evening peak the total vehicle volume towards Colombo is around 1300 vph (see Figure 3). The total two directional flow was around $3950 \mathrm{vph}$ which was less than the morning peak flow. This can clearly be seen in Figure 3.

There are several models available to compute the travel time [3].

(i) The Bureau of Public Roads (BRP) model used in the UK, (ii) Greenshields model, and (iii) Davidson's model are few models that could be used in computing the travel time benefits or losses.

It was decided to use Davidson's model [4], to compute the travel time benefits or losses since it suited better with local parameters and for better relative accuracy. Davidson's model considers parameters such as type of road, road width, frequency of signals, pedestrian crossings, and parked vehicles etc.

Davidson [4] successfully used the following model to compute travel time differences for varying lane options for urban arterial roads as well as freeways.

$$
t=t_{0} \times\left[\frac{1-(1-j) y}{(1-y)}\right]
$$

Where,

$t$ - travel time at traffic flow $q$

$t_{0}$ - time taken to travel with no other traffic (i.e., zero flow travel time)

$q$ - traffic flow (veh/hr/lane)

S - saturation flow (veh/hr/lane)

$y=q / s$

$j$ - level of service parameter

$j$ is the Level of Service (LOS) parameter which is related to the type of road, road width, frequency of signals, pedestrian crossings, and parked vehicles. Blunden and Black [5] suggest following values for $j$.

$j=0$ to 0.2 for freeways

$j=0.4$ to 0.6 for urban arterials

$j=1$ to 1.5 for collector roads

Hence it is reasonable to assume $j=0.5$ for Colombo - Kandy road. 
Zero flow travel time $\left(t_{0}\right)$ was taken as 2 minutes assuming a desired speed of $60 \mathrm{~km} / \mathrm{h}$ over the study distance of $2 \mathrm{~km}$ with no other traffic.

This study intends to consider several options of lane operations between Pattiya junction and New Kelani Bridge roundabout. This road stretch of $2 \mathrm{~km}$ in length (Figure 4) consists of 3 lanes in each direction.

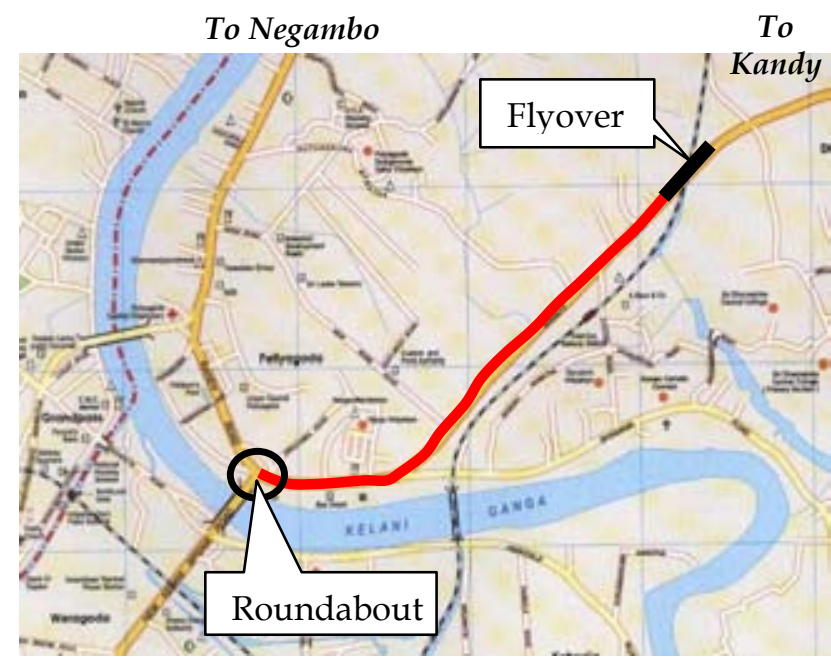

Figure 4 - Site Layout

\section{Morning Peak Flows:}

Option ( 1 ) - During the morning peak, to have 4 lanes (with mixed traffic) operating towards Colombo bound direction, and 2 lanes (with mixed traffic) operating for out of Colombo traffic as shown in Figure 5.

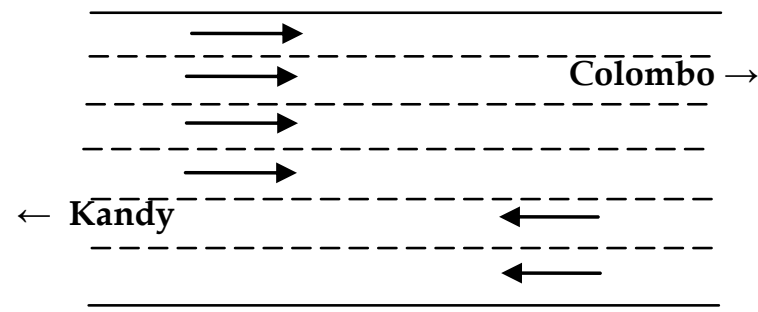

Figure 5 - Lane Operation Option ( 1 )

Option ( 2 ) - During the morning peak, to have 3 lanes (with mixed traffic) and another lane exclusively for buses operating towards Colombo inbound direction, and 2 lanes (with mixed traffic) operating for out of Colombo traffic as shown in Figure 6.

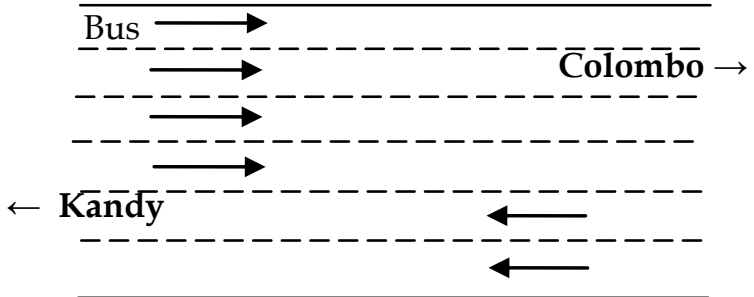

Figure 6 - Lane Operation Option ( 2 )

\section{Evening Peak Flows:}

Option ( 3 ) - During the evening peak, to have 4 lanes (with mixed traffic) operating towards out of Colombo direction, and 2 lanes (mixed traffic) operating towards Colombo as shown in Figure 7.

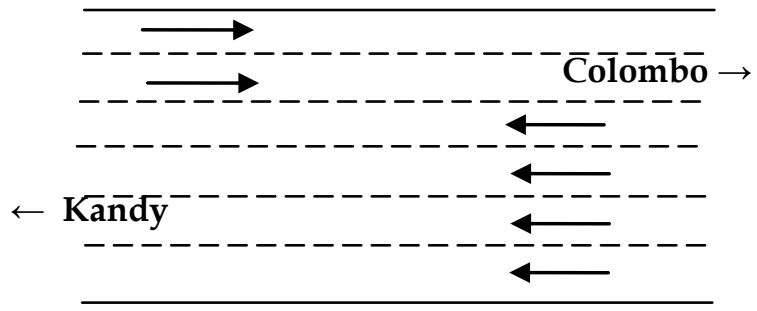

Figure 7 - Lane Operation Option ( 3 )

Option ( 4 ) - During the evening peak, to have 3 lanes (with mixed traffic) and another lane exclusively for buses for traffic going out of Colombo, and 2 lanes (with mixed traffic) for Colombo bound traffic as shown in Figure 8.

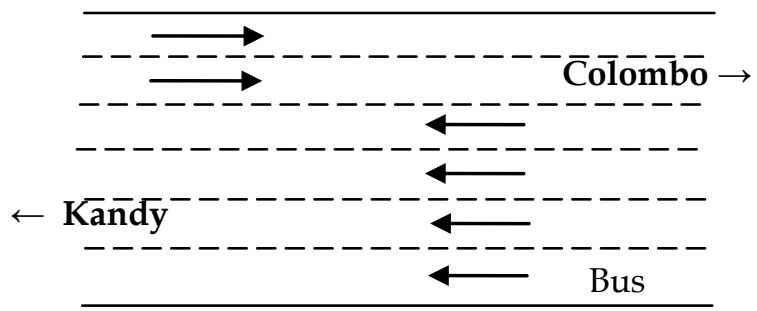

Figure 8 - Lane Operation Option ( 4 )

Davidson's model was applied to compute the benefits or losses of saving on travel time, and then the best options were selected. Computation is summarised in Tables 4 \& 5 respectively for morning and evening peak flows. 
Table 4 - Application of Davidson's Model for Two Directional Traffic in the Morning Peak

To Colombo Direction (PHF 7:00AM to 8:00AM)

\begin{tabular}{|c|c|c|c|c|c|c|c|}
\hline & \multicolumn{2}{|c|}{ Existing } & \multicolumn{2}{|c|}{ Option (1) } & \multicolumn{3}{|c|}{ Option ( 2) } \\
\hline & $\begin{array}{c}\text { Mixed } \\
----> \\
---> \\
--->>\end{array}$ & $\begin{array}{c}\begin{array}{c}\text { Mixed } \\
<---- \\
<--- \\
<---\end{array} \\
\end{array}$ & $\begin{array}{c}\text { Mixed } \\
----> \\
----> \\
----> \\
---->\end{array}$ & $\begin{array}{c}\text { Mixed } \\
<---- \\
<----\end{array}$ & $\begin{array}{l}\text { Bus } \\
--->\end{array}$ & $\begin{array}{c}\text { Mixed } \\
----> \\
---> \\
---->\end{array}$ & $\begin{array}{c}\text { Mixed } \\
<---- \\
<---\end{array}$ \\
\hline $\mathrm{vph}$ & 3050 & 1150 & 3050 & 1150 & 350 & 2700 & 1150 \\
\hline (Bus/hr) & 350 & 220 & 350 & 220 & 350 & - & 220 \\
\hline pcu & 3615 & 1550 & 3615 & 1550 & 700 & 2910 & 1550 \\
\hline Lanes & 3 & 3 & 4 & 2 & 1 & 3 & 2 \\
\hline $\mathrm{q}$ & 1205 & 517 & 904 & 775 & 700 & 970 & 775 \\
\hline $\mathrm{s}$ & 2000 & 2000 & 2000 & 2000 & 2000 & 2000 & 2000 \\
\hline$y=q / s$ & 0.603 & 0.259 & 0.452 & 0.388 & 0.350 & 0.485 & 0.388 \\
\hline $\mathrm{j}$ & 0.5 & 0.5 & 0.5 & 0.5 & 0.5 & 0.5 & 0.5 \\
\hline $\mathrm{T}$ & 2 & 2 & 2 & 2 & 2 & 2 & 2 \\
\hline $\mathrm{t}=$ travel time & 3.516 & 2.349 & 2.825 & 2.633 & 2.538 & 2.942 & 2.633 \\
\hline Occupancy - M & 3.25 & 3.25 & 3.25 & 3.25 & 50 & 3.25 & 3.25 \\
\hline Occupancy - B & 50 & 50 & 50 & 50 & & & 50 \\
\hline Persons & 26275 & 14022.5 & 26275 & 14022.5 & 17500 & 8775 & 14022.5 \\
\hline Passenger minutes & 92375.63 & 32933.49 & 74222.08 & 36916.38 & 44423.08 & 25813.83 & 36916.38 \\
\hline Benefit / Loss & - & - & 18153.55 & -3982.89 & 221 & 8.72 & -3982.89 \\
\hline & & & B & $\mathrm{L}$ & & & $\mathrm{L}$ \\
\hline Net Benefit / Loss & & & 141 & 0.66 & & 18155.8 & \\
\hline
\end{tabular}

Table 5 - Application of Davidson's Model for Two Directional Traffic in the Evening Peak

To Kandy Direction (PHF 7:00AM to 8:00PM)

\begin{tabular}{|c|c|c|c|c|c|c|c|}
\hline & \multicolumn{2}{|c|}{ Existing } & \multicolumn{2}{|c|}{ Option ( 3 ) } & \multicolumn{3}{|c|}{ Option (4) } \\
\hline & $\begin{array}{c}\text { Mixed } \\
----> \\
---> \\
---->\end{array}$ & $\begin{array}{c}\begin{array}{c}\text { Mixed } \\
<---- \\
<--- \\
<---\end{array} \\
\end{array}$ & $\begin{array}{c}\text { Mixed } \\
----> \\
--->>\end{array}$ & $\begin{array}{c}\text { Mixed } \\
<---- \\
<---- \\
<---- \\
<----\end{array}$ & $\begin{array}{c}\text { Mixed } \\
----> \\
--->>\end{array}$ & $\begin{array}{c}\text { Mixed } \\
<---- \\
<--- \\
<---\end{array}$ & $\begin{array}{l}\text { Bus } \\
<--\end{array}$ \\
\hline $\mathrm{vph}$ & 1300 & 2650 & 1300 & 2650 & 1300 & 2310 & 340 \\
\hline (Bus/hr) & 225 & 340 & 225 & 340 & 225 & - & 340 \\
\hline pcu & 1690 & 3330 & 1690 & 3330 & 1690 & 2650 & 680 \\
\hline Lanes & 3 & 3 & 2 & 4 & 2 & 3 & 1 \\
\hline $\mathrm{q}$ & 565 & 1110 & 845 & 835 & 845 & 885 & 680 \\
\hline $\mathrm{s}$ & 2000 & 2000 & 2000 & 2000 & 2000 & 2000 & 2000 \\
\hline$y=q / s$ & 0.283 & 0.555 & 0.423 & 0.418 & 0.423 & 0.443 & 0.340 \\
\hline $\mathrm{j}$ & 0.5 & 0.5 & 0.5 & 0.5 & 0.5 & 0.5 & 0.5 \\
\hline $\mathrm{T}$ & 2 & 2 & 2 & 2 & 2 & 2 & 2 \\
\hline $\mathrm{t}=$ travel time & 2.394 & 3.247 & 2.732 & 2.717 & 2.732 & 2.794 & 2.515 \\
\hline Occupancy - M & 3.25 & 3.25 & 3.25 & 3.25 & 3.25 & 3.25 & 50 \\
\hline Occupancy - B & 50 & 50 & 50 & 50 & 50 & & \\
\hline Persons & 14744 & 24508 & 14744 & 24508 & 14744 & 7507.5 & 17000 \\
\hline Passenger minutes & 35292.53 & 79580.53 & 40274.05 & 66580.46 & 40274.05 & 20973.87 & 42757.58 \\
\hline Benefit / Loss & - & - & -4981.52 & $\begin{array}{c}13000.07 \\
B\end{array}$ & -4981.52 & & 9.09 \\
\hline Net Benefit / Loss & & & 801 & .55 & & 10867.5 & \\
\hline
\end{tabular}




\section{Findings of the Study}

From Table 4 it could be seen that the introduction of a new mixed lane towards Colombo during the morning peak will have a net reduction in travel time by 14,170 passenger minutes during the peak hour. If one of the in-bound lanes is designated to buses only, there will be a reduction in travel time by 18,155 passenger minutes. Hence converting a lane towards Colombo direction is advantageous, and if this lane is designated to buses only the advantage is higher.

Similarly from Table 5 it could be seen that the introduction of a new mixed lane for vehicles travelling out of Colombo in the evening peak will have a net reduction in travel time by 8,018 passenger minutes during the peak hour. If one of the outbound lanes is designated to buses only, there will be a reduction in travel time by 10,867 passenger minutes.

It was found that introduction of a reversible lane (mix or buses only) towards Colombo bound traffic was advantageous from 6:00AM to 9:00AM, since during this period Colombo bound traffic volume increases above $2000 \mathrm{vph}$ (see Figure 3). Therefore, a 4th lane towards Colombo during this period is found to be beneficial to the system. Similarly, introduction of a 4th lane for out-bound traffic which is above $2000 \mathrm{vph}$ from 5:30PM to 8:30PM (see Figure 3) is also beneficial.

\section{Conclusions}

From options (1) \& (3), it is observed that benefits can be obtained by introduction of reversible lanes during morning and evening peaks for mixed traffic, to enhance the road efficiency during peak flows.

From options (2) \& (4) results it is clear that introduction of designated lanes 'only for buses' will further improve the overall efficiency of the system. If 'buses only' lanes are introduced it is of the utmost importance to reserve these lanes only for buses as expected. To obtain the maximum benefits it should be ensured that buses will not enter the mixed traffic lanes. If this enforcement is neglected it can end up as a failure as shown in [6].

When implementing the reversible flow lanes, careful attention should be paid to the intersection at the turn-off to Biyagama road, and also to the terminal at New Kelani Bridge roundabout to ensure smooth flow of traffic at these critical points.

If the proposed scheme is implemented, one operational advantage is that, since this road stretch is located adjoining the Peliyagoda Police Station, strict implementation is possible with close supervision from the Peliyagoda traffic police division.

It is important that when flow direction is changed in reversible flow lanes, to pay the utmost care by the implementers towards the safety of the drivers during the transition. It is also important that strict lane discipline be maintained by all drivers for obtaining maximum benefits while ensuring safety of all the road users.

\section{References}

1. Kadiyali, L. R., 'Traffic Engineering and Transport Planning', Khanna Publishers, 2B, Nath Market, Nai Sarak, Delhi, India, 1997.

2. Salter, R. J. and Hounsell, N. B., 'Highway Traffic Analysis and Design', MACMILLAN Press Ltd., London, 1996.

3. Khisty, C. J. and Kent Lall, B., 'Transportation Engineering - An Introduction' 2nd Ed. Prentice-Hall International, Inc., New Jersey, 1998.

4. Davidson, K. B., 'A Flow Travel time Relationship for Use in Transport Planning', Proceedings, Australian Road Research Board 3, 1966.

5. Blunden, W. R. and Black, J. A., 'The Land Use / Transportation System, 2nd Ed. Pergamon Press, Elmsford, NY, 1984.

6. Weerasekera, K. S., 'Trial Introduction of a Bus Lane on A02: A Post-mortem', ENGINEER Journal of The Institution of Engineers, Sri Lanka, Vol. 43, No. 03, pp. 53-56, The Institution of Engineers, Sri Lanka, July 2010. 